\title{
Modelling of damage patterns of RC concrete columns under demolition by blasting
}

\author{
M. K. Zidan ${ }^{1}$, M. N. Fayed ${ }^{2}$, A. M. Elhosiny ${ }^{2}$, K. M. Abdelgawad ${ }^{3}$ \\ \& H. H. Orfy ${ }^{4}$ \\ ${ }^{1}$ Faculty of Engineering, Future University, Egypt \\ ${ }^{2}$ Department of Structural Engineering, Faculty of Engineering, \\ Ain Shams University, Egypt \\ ${ }^{3}$ Police Academy, Egypt \\ ${ }^{4}$ Faculty of Engineering, Egyptian Russian University, Egypt
}

\begin{abstract}
A numerical study for damage of RC columns under demolition blasting has been carried out and the results were compared with available experimental work. Basic considerations for the finite element method of the LS-DYNA Program are introduced. Equations of state models as well as three constitutive material models (the concrete mass, the reinforcing steel, and the high energy explosive material) are described in detail. In the present work, three Finite Element modeling of steel bars as beam, solid elements or by converting reinforcement quantity into concrete solid elements have been examined through comparison with available experimental work. The influence of different parameters on the blasting damage pattern of RC columns has been investigated. These parameters include steel rebar arrangement, explosive factors and the concrete strength of columns. The results have been presented and discussed.

Keywords: demolition, blast, damage pattern, $R C$ column, explosive factors, $L S$ DYNA, experimental results, solid element, beam element, finite element models.
\end{abstract}

\section{Introduction}

Since the number of ageing reinforced concrete (RC) buildings increases, demand for demolishing those structures may rapidly increase. To demolish the $\mathrm{RC}$ buildings, blast demolition techniques are quite popular in Europe and the United States, in which small explosive charges are used to knock down the $\mathrm{RC}$ buildings completely in a very short period of time (Loizeaux and Osborn 
[1]). Compared with conventional demolition techniques with heavy machinery such as a wrecking ball, hydraulic hammer, excavator, hydraulic shear, hydraulic hammer, etc., the major advantages of blasting demolition are: (1) the short period of the demolition process, (2) the limited use for heavy machinery and (3) cost effectiveness and time saving.

From a physics point of view, blasting demolition consists of two dynamic stages: The first stage is the wave propagation and development of fracture network in the structure upon detonation of explosives; and the second stage is the collapse of the structure, weakened by dynamic fracture, due to the gravitational effect. Previous studies on structural demolition by blasting has mainly handled the second stage (Mattern et al. [2, 3], Isobe et al. [4]) while the physical phenomena at the first stage have been most often ignored, partly because of mathematical complexities involved in that stage.

The safe destruction of a structure by controlled blasting requires detailed and reliable knowledge about impact, wave dynamics and fracture mechanism related to blast waves. Numerical simulations of exploding the RC elements phenomenon are presented in Riisgaard et al. [5]. Also, Fujikake and Aemlaor [6] performed a qualitatively and quantitatively investigation about the damage of RC columns under demolition blasting. Lupoae et al. [7] proposed a singledegree of freedom model to assess the influence of the reinforcement on demolition of the RC beams or columns using explosive charges placed in boreholes.

In the present paper, a numerical study for damage of $\mathrm{RC}$ columns under demolition blasting has been carried out and the damage patterns were compared with the experimental work performed by Fujikake and Aemlaor [6]. The influence of different parameters on the blasting damage pattern of RC columns has been investigated. These parameters include: steel rebar arrangement, explosive factors, and concrete strength of columns. In addition, for blasting demolition of RC columns, modeling steel bars as beams, solid elements or by converting reinforcement quantity into concrete solid elements has been examined through comparison with the available experimental work. Our goal here, therefore, is to establish a firm but concise technique to simulate the physical process, especially that for the first stage, of blasting demolition of realistic structure and columns elements.

\section{Method of analysis by LS-DYNA program}

LS-DYNA, which is a general purpose Finite Element Code for analyzing the large deformation dynamic response of structures, has been available since the late 1980s, and has been extensively validated against experimental results (Agardh [8], Lippanen [9]). The main solution methodology is based on explicit time integration.

In the numerical simulations through the present work, the partial differential equations governing the basic physics principles of conservation of mass, momentum, and energy are employed. The equations to be solved are both time and space-dependent and nonlinear in nature. These equations, together with 
Equations of State (EOS) and constitutive models describing material behavior and a set of initial and boundary conditions, define the complete system for blast simulations. This analysis is carried out using the commercial program LSDYNA.

\section{Material models}

An important aspect of finite element modelling is the establishment of material constitutive models, which represent the real behaviour of the structure in question. The material models in the LS-DYNA constitutive model library are more than capable of accurately simulating the actual material behaviour in the structure. The material models chosen for simulation will depend on the physical properties of materials. There are three types of materials involved in the problem under investigation, namely the concrete mass, the reinforcing steel, and the high energy explosive material.

\subsection{Concrete Winfrith model (model 084)}

The primary constitutive model applied was the Concrete Winfrith model, Material type 084, which is suitable for R.C. columns, beams and slab elements. This model was developed by Neilson et al. [10] and Broadhouse [11] over many years and has been validated against experiments. Degenerated eight-node solid elements with variable size were used to model the concrete volume. The model includes tensile cracking behaviour, compressive crushing behaviour, and reinforcement yield, hardening and failure behaviour. Element eroding technique is used to avoid severe element distortion during the simulation of blast load effects.

\subsection{Steel bar model (model 3)}

This model is suited to model isotropic and kinematics hardening plasticity with the option of including rate effects. It is a very cost effective model and is available for beam, shell, and solid elements. Isotropic, kinematics, or a combination of isotropic and kinematics hardening may be obtained by varying a parameter, called $\beta$ between 0 and 1 . For $\beta$ equal to 0 and 1 , respectively, kinematics and isotropic hardenings are obtained. Krieg and Key [12] formulated this model and the implementation is based on their paper.

\subsection{Explosive material model (model 8)}

The high explosive material is modelled using equations of state. Equation of state model is used in LS-DYNA to relate the internal element energy, pressure, density, and volume of specified materials. A number of empirical EOS has been developed for high explosives. Of the EOS identifiers, Jones-Wilkins-Lee (JWL) is the most popular and is easily calibrated. The JWL equation of state defines pressure as a function of relative volume, $\mathrm{V}$, and internal energy per initial volume, E, as 


$$
\mathrm{P}=\mathrm{C}_{1}\left(1-\frac{\omega}{\mathrm{r}_{1} \mathrm{v}}\right) \mathrm{e}^{-\mathrm{r}_{1} \mathrm{v}}+\mathrm{C}_{2}\left(1-\frac{\omega}{\mathrm{r}_{2} \mathrm{v}}\right) \mathrm{e}^{-\mathrm{r}_{2} \mathrm{v}}+\frac{\omega \mathrm{e}}{\mathrm{v}}
$$

where $C_{1}, C_{2}, r_{1}$ and $r_{2}$ are constants and e, $\omega$ and $v$ are the internal energy, adiabatic constant and specific volume respectively, and its values for many common explosives have been determined from dynamic experiments.

\section{Numerical study for the damage of RC columns under demolition by blasting compared with available experimental data}

\subsection{Description of RC column specimens}

The effects of concrete strength and longitudinal and shear reinforcing bars set in $\mathrm{RC}$ columns on the damage of the RC columns by explosive charges have been investigated in this study. The amount of explosive used, the longitudinal and shear reinforcement ratios, and concrete compressive strength of the RC column specimens tested by Fujikake and Aemlaor [6] were chosen as experimental parameters.

Different concrete strengths and rebar arrangements were tested by Fujikake and Aemlaor [6] (Figure 1). The specimen designations are given in Figures 2, 3 and 4. All the RC column specimens were $180 * 180 \mathrm{~mm}$ in cross section and $1200 \mathrm{~mm}$ long. The RC column specimens were reinforced with $10 \mathrm{~mm}$ deformed steel bars with a nominal yield strength of $345 \mathrm{MPa}$ and $3 \mathrm{~mm}$ stirrups steel wires with a nominal yield strength of $400 \mathrm{MPa}$. The compressive strengths of concrete were 51.6 and $90.3 \mathrm{MPa}$.

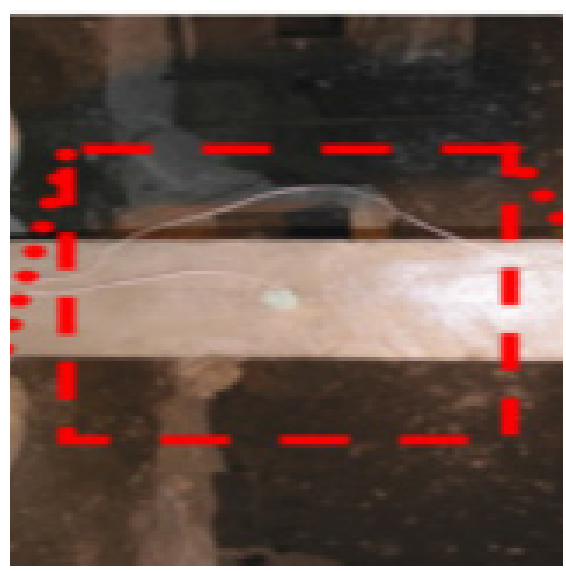

Figure 1: Blasting test for RC column specimen (Fujikake and Aemlaor [6]). 


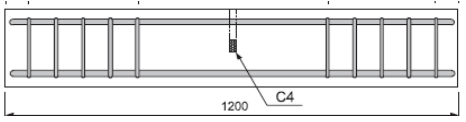

(a) Side view of Fc50P09H0

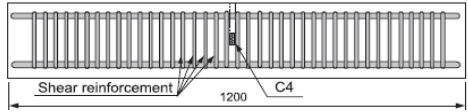

(c) Side view of Fc50P09H26

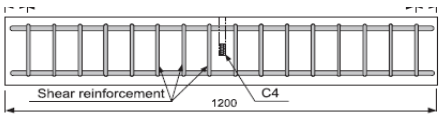

(b) Side view of Fc50P09H10

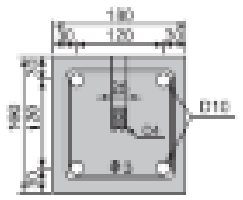

Cross section

Figure 2: $\mathrm{RC}$ column specimens with a longitudinal reinforcement ratio of 0.9\% (Fujikake and Aemlaor [2011]).

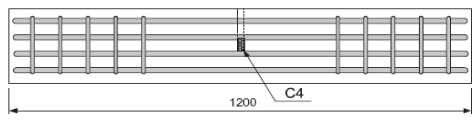

(a) Side view of Fc50P25H0

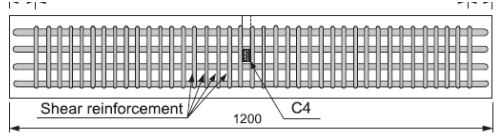

(c) Side view of Fc50P25H26

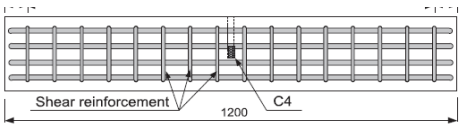

(b) Side view of Fc50P25H10

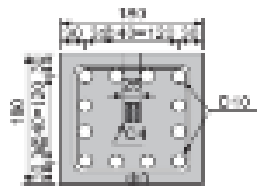

Cross section

Figure 3: RC column specimens with a longitudinal reinforcement ratio of $2.5 \%$ (Fujikake and Aemlaor [6]).

\subsection{Mathematical models}

A detailed modeling of the columns described previously has been built in LSDYNA $[13,14]$. For finite element simulation of the columns, explicit solver in LS-DYNA has been chosen since it can handle a large number of elements. The dimensions of the specimen are the same as those for the field experiment.

Degenerated eight-node solid elements with variable size were used to model the concrete volume. The Winfrith model, Material type 084, in LSDYNA, was employed to represent concrete (cylinder strength $=50 \mathrm{MPa}$, tensile strength $=$ $5 \mathrm{MPa}$ ) for the columns (Figure 5). Element eroding technique is used to avoid severe element distortion during the simulation of blast load effects. Ultimate strain failure used for solid concrete elements is 0.01 . 


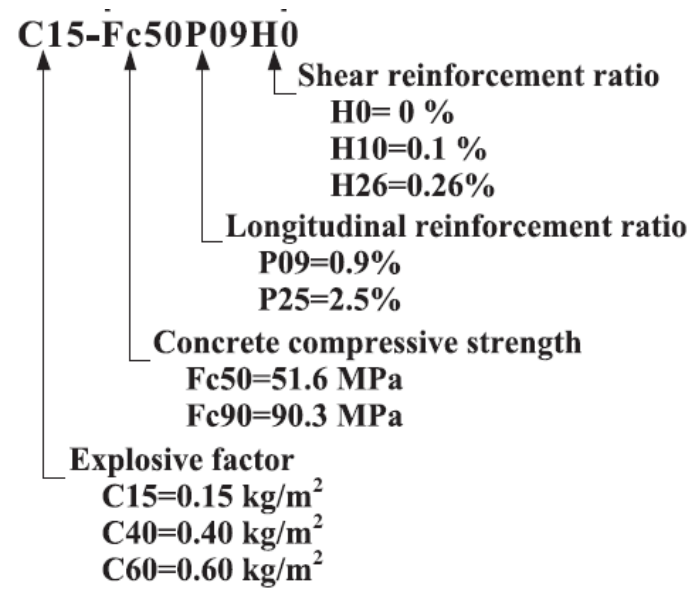

Figure 4: Specimen designations (Fujikake and Aemlaor [6]).

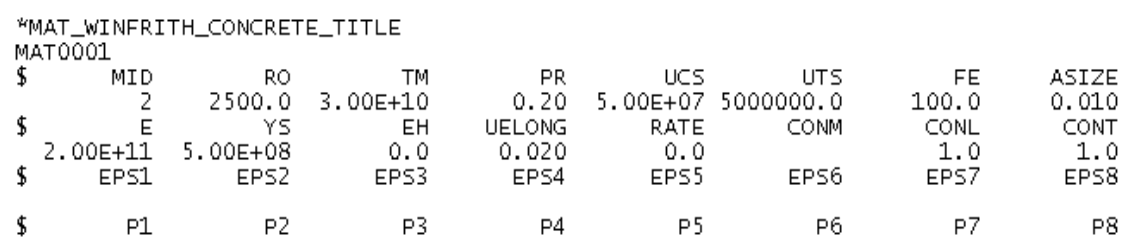

Figure 5: Material input card for concrete element.

A detailed modeling of steel reinforcement is important for the simulation of blast load effects on concrete structures. Generally, steel bars for reinforced concrete members are modeled as a beam element that can represent combined behavior of both concrete and steel during hazards such as earthquakes, wind, etc. However, this type of element may not be appropriate for reinforced concrete members subject to blast loads. In the present work, three finite element modelings of steel bars have been considered:

(i) Finite element modeling of steel as beam element;

(ii) Finite element modeling of steel as solid element;

(iii) Finite element modeling of steel by converting the reinforcement quantity into equivalent concrete solid elements.

Steel bars in the column are modeled using Plastic Kinematic material model (MAT_3), assuming that a perfect bond exists between concrete and rebar at the shared nodes. Many investigators have examined stress-strain relationship of reinforced concrete at high strain rates and have shown experimentally that ultimate strain values are almost constant (Malvar and Ross [15], Zeng et al. [16]). Ultimate strain failure used in the simulation of the steel bars is taken 0.35. The nominal yield strength of the longitudinal steel bars is $345 \mathrm{MPa}$ while for steel stirrup is $400 \mathrm{MPa}$. Figure 6 shows material input card for steel bars. 


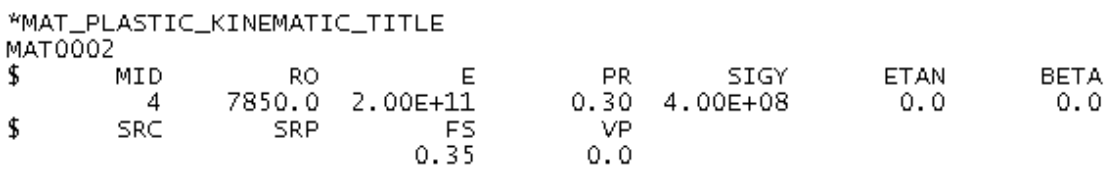

Figure 6: Material input card for steel bars.

The explosive material designated as Material type 08 in LS-DYNA, was employed to represent explosive. *MAT_HIGH_EXPLOSIVE_BURN and the command *INITIAL_DETONATION are used within this model. After ignition, the evolution of the explosive charge is controlled by the Jones-Wilkins-Lee (JWL) equation of state. Parameters for equation of state JWL for C4 explosives are used from Mader [17] and Alia and Souli, [18].

The finite element model of the reinforced concrete column has been prepared for LS-DYNA program. The mesh of the concrete volume of the column is shown in Figure 7. Figures 8(a)-(c) show finite element modeling of steel bars as solid elements for longitudinal reinforcement ratio of $0.9 \%$ with shear reinforcement ratios $0.0,0.1$ and $0.26 \%$ respectively. Similarly, Figures 9 (a)-(c) show finite element modeling of steel bars as solid elements for longitudinal reinforcement ratio of $2.5 \%$ with shear reinforcement ratios $0,0.1$ and $0.26 \%$ respectively.

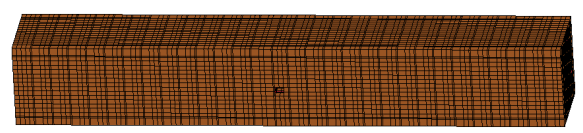

Figure 7: Solid concrete elements.

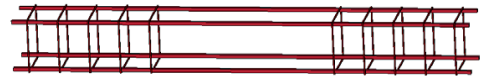

(a) shear reinforcement ratio $\mathrm{H} 0$

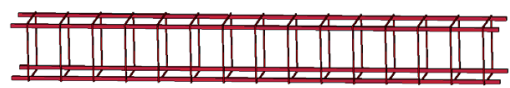

(b) shear reinforcement ratio $\mathrm{H} 10$

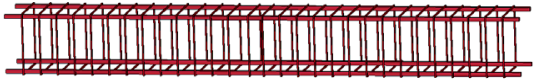

(c) shear reinforcement ratio $\mathrm{H} 26$

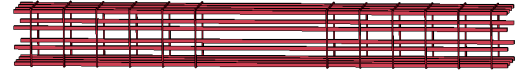

(a) shear reinforcement ratio $\mathrm{H} 0$

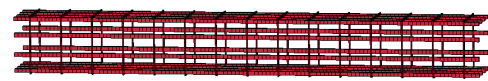

(b) shear reinforcement ratio $\mathrm{H} 10$

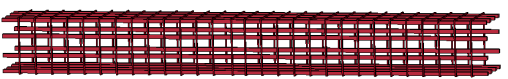

(c) shear reinforcement ratio $\mathrm{H} 26$

Figure 9: Solid steel elements for longitudinal reinforcement ratio of $2.5 \%$

Figure 8: Solid steel elements for longitudinal reinforcement ratio of $0.9 \%$. 


\subsection{Cases of study}

The following cases of study have been considered for damage of RC columns by explosions:

I. Validity of different finite element modeling of steel bars, (steel bars modeled as solid elements, beam elements and equivalent reinforcement quantity in concrete elements).

II. Influence of rebar arrangement on damage of RC column by explosion using different longitudinal reinforcement ratios $0.9 \%$ and $2.5 \%$ with shear reinforcement ratios $0.1 \%$ and $0.26 \%$ respectively, (steel bars modeled as solid elements).

III. Explosive factors of $0.15,0.4$ and $0.6 \mathrm{~kg} / \mathrm{m}^{2}$ with fc50, for concrete grade 50 with longitudinal reinforcement ratio $2.5 \%$ and with shear reinforcement ratio $0.26 \%$, (steel bars models as solid element).

IV. Concrete grade strength 50 and 90 for longitudinal reinforcement ratio $0.9 \%$ with shear reinforcement ratios $0 \%$ and explosive factor of 0.15 $\mathrm{kg} / \mathrm{m}^{2}$, (steel bars modeled as solid elements).

\subsection{Results and discussion}

\section{(I) Validity of different finite element modeling of steel bars}

The validity of finite element modeling of steel bars as solid element, beam element or equivalent reinforcement quantity in concrete elements in blasting demolition of $\mathrm{RC}$ column has been examined and compared for two different values of concrete erosion (ultimate strain failure). Figures 10 through 13 show shapes of the damaged RC column specimens obtained by the blasting case of $\mathrm{C} 15-\mathrm{Fc} 50 \mathrm{P} 25 \mathrm{H} 26$ and $\mathrm{C} 15-\mathrm{Fc} 50 \mathrm{P} 09 \mathrm{H} 26$ for concrete erosion 0.01 and 0.02 respectively.

Figures 10(a), 11(a), 12(a) and 13(a) indicate that modeling steel bars as beam elements do not agree with the experimental test results carried out by Fujikake and Aemlaor [6] (Figures 10(d), 11(d), 12(d) and 13(d)).

Further, the results obtained in Figures 10(b), 11(b), 12(b) and 13(b) for modeling steel bars as equivalent concrete elements are much better confirming with the experimental results. These results are still not matching identically with the experimental test results. On the other hand, the results obtained in Figures 10(c), 11(c), 12(c) and 13(c) for modeling steel bars as solid elements are in good agreement with the experimental test results. With respect to concrete erosion value (ultimate strain failure), the results indicate that using concrete erosion value 0.02 instead of 0.01 gives damage shapes more close to experimental tests. The concrete erosion value 0.01 is a practical value, however under the action of blast loads, some researchers assumed higher values of failure strain $[14,19]$. 


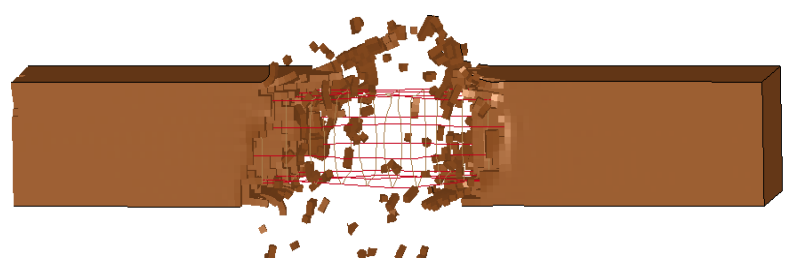

(a) Modeling of steel bars as beam elements

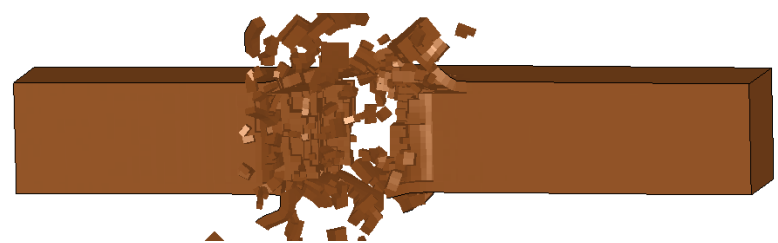

(b) Modelling of steel bars as equivalent concrete elements

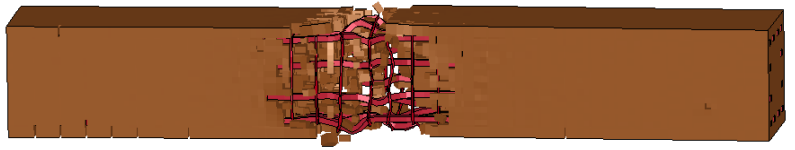

(c) Modelling of steel bars as solid elements

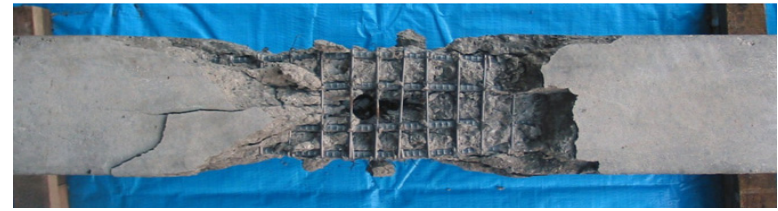

(d) Experimental (Fujikake and Aemlaor [6])

Figure 10: Influence of rebar modelling on damage of RC column specimens with a compressive strength of $51.6 \mathrm{MPa}$, a longitudinal reinforcement ratio of $2.5 \%$ and shear reinforcement ratio of $0.26 \%$ - concrete erosion $=0.01(\mathrm{C} 15$ FC50 P25 H26).

(II) Influence of rebar arrangement on damage of RC column by explosion C4 explosive with a weight of $5 \mathrm{~g}$ corresponding to an explosive factor of $0.15 \mathrm{~kg} / \mathrm{m}^{2}$ was applied on the RC column specimens with different rebar arrangement (Figures 8 and 9). In this study, finite element modeling of concrete volume and steel bars as solid elements in blasting demolition of RC column has been adopted. 


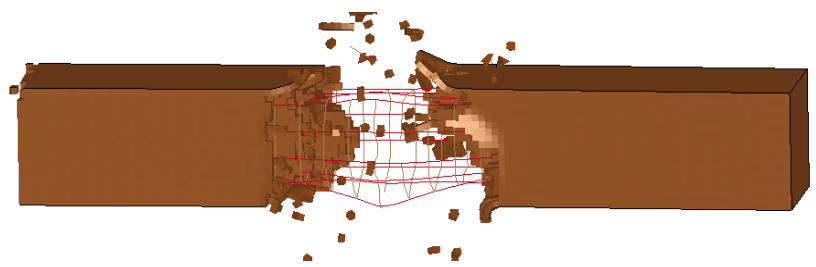

(a) Modeling of steel bars as beam elements

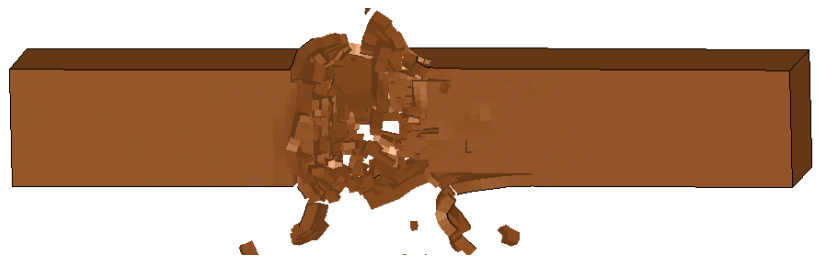

(b) Modeling of steel bars as equivalent concrete elements

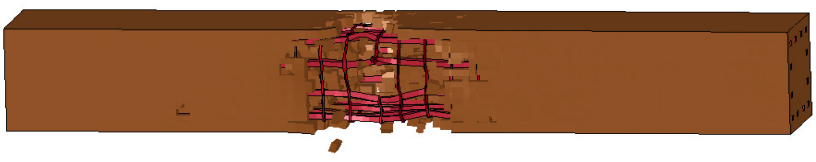

(c) Modeling of steel bars as solid elements

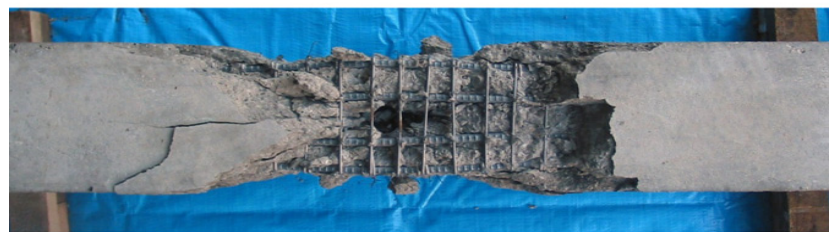

(d) Experimental (Fujikake and Aemlaor [6])

Figure 11: Influence of rebar modelling on damage of RC column specimens with a compressive strength of $51.6 \mathrm{MPa}$, a longitudinal reinforcement ratio of $2.5 \%$ and shear reinforcement ratio of $0.26 \%-$ concrete erosion $=0.02(\mathrm{C} 15 \mathrm{FC} 50 \mathrm{P} 25 \mathrm{H} 26)$.

Figures 14 and 15 show shapes of the damaged RC column specimens obtained by blasting cases of C15-Fc50P09H0, C15-50P09H10, C15FcP09H26, C15-Fc50P25H0, C15-Fc50P25H10 and C15-Fc50P25H26, using LSDYNA program respectively.

Figures 14 and 15 show that the results obtained by LS-DYNA program for damaged RC column specimens are in good agreement with the experimental test results carried out by Fujikake and Aemlaor [6]. Further, the results of the 


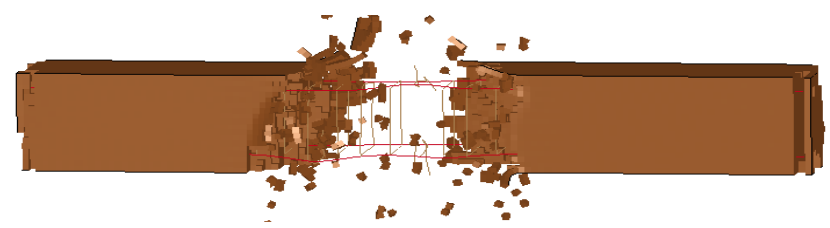

(a) Modelling of steel bars as beam elements

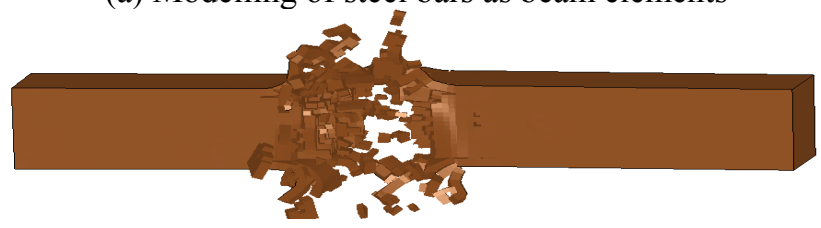

(b) Modelling of steel bars as equivalent concrete elements

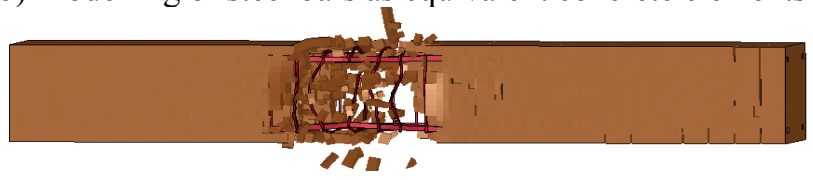

(c) Modelling of steel bars as solid elements

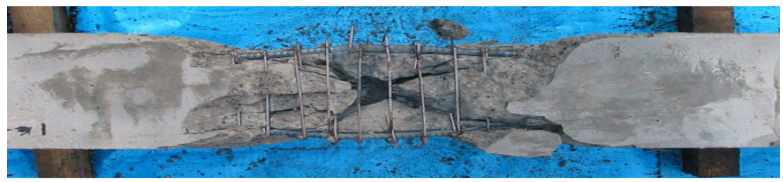

(d) Experimental (Fujikake and Aemlaor [6])

Figure 12: Influence of rebar modelling on damage of RC column specimens with a compressive strength of $51.6 \mathrm{MPa}$, a longitudinal reinforcement ratio of $0.9 \%$ and shear reinforcement ratio of $0.26 \%$ concrete erosion $=0.01(\mathrm{C} 15$ FC50 P09 H26).

model indicate that the more amount of longitudinal and shear reinforcement are provided, the less easily the core concrete is shattered and cleared. In addition, the lengths of the exposed longitudinal bars are clearly decreased with an increase in shear reinforcement ratio. Therefore, this fact strongly supports that shear reinforcing bars should be removed within a certain region before explosions.

\section{(III) Influence of explosive factors on the damage of RC columns}

In this section, the influence of explosive factors on the damage of RC columns has been examined. Figure 16 shows the damaged RC column specimens obtained from the blasting tests for Fc50P25H26 specimens, in which the explosive factor, as a main variable, was set at $0.15,0.40$ and $0.60 \mathrm{~kg} / \mathrm{m}^{2}$. 


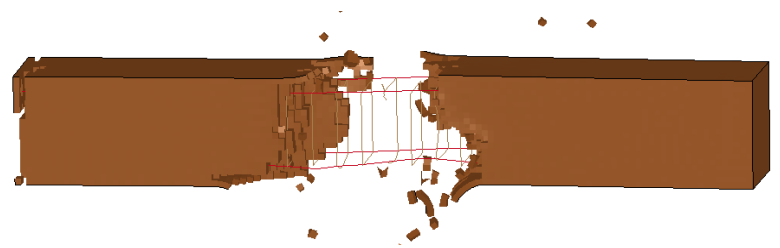

(a) Modelling of steel bars as beam elements

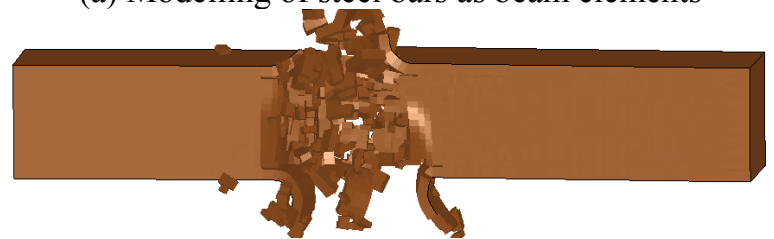

(b) Modelling of steel bars as equivalent concrete elements

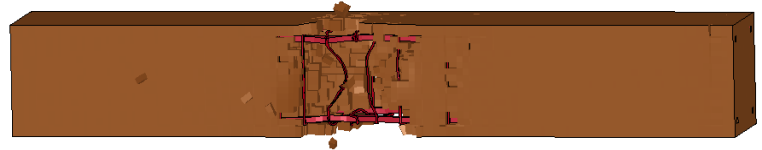

(c) Modeling of steel bars as solid elements

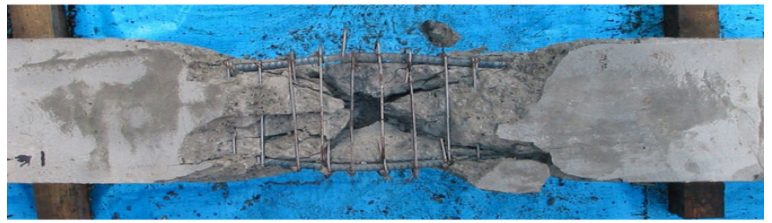

(d) Experimental (Fujikake and Aemlaor [6])

Figure 13: Influence of rebar modelling on damage of RC column specimens with a compressive strength of $51.6 \mathrm{MPa}$, a longitudinal reinforcement ratio of $0.9 \%$ and shear reinforcement ratio of $0.26 \%$ concrete erosion $=0.02(\mathrm{C} 15$ FC50 P09 H26).

For explosive factors $\mathrm{C} 60$ and $\mathrm{C} 40$, the concrete core of specimens was completely shattered and cleared (Figures 16(a) and (b)). The explosive factor of $0.15 \mathrm{~kg} / \mathrm{m}^{2}$, however, is not enough to blow up the concrete core of Fc50P25H26 with a shear reinforcement ratio of $0.26 \%$ (as shown in Figure 16(c)).

From Figure 16, it can be observed that the volume of fragmented concrete by the explosion increases with the increase in the explosive factor. To shatter and clear the concrete core of $\mathrm{Fc} 50 \mathrm{P} 25 \mathrm{H} 26$, the explosive factor should be set at 0.4 $0.6 \mathrm{~kg} / \mathrm{m}^{2}$. It should be noted that it is impossible to cut the longitudinal rebar's by the explosion in a blasting hole, while it may be possible to blow the shear rebar's off by this technique 


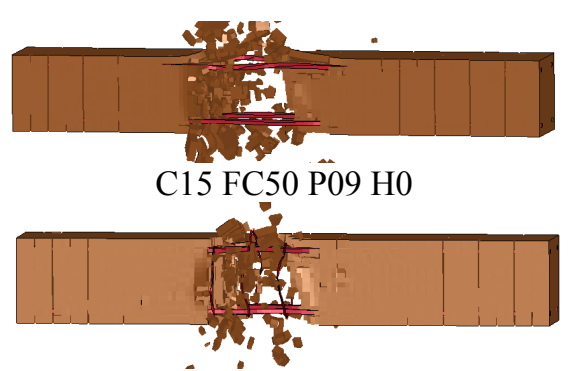

C15 FC50 P09 H10

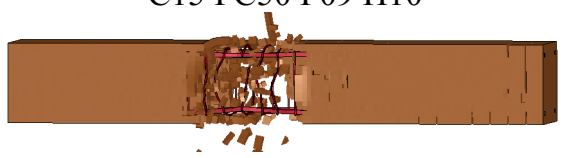

C15 FC50 P09 H26

Present work

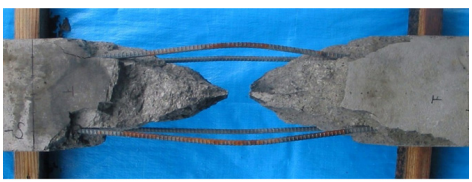

(a) $\mathrm{C} 15-\mathrm{Fc} 50 \mathrm{P} 09 \mathrm{H} 0$

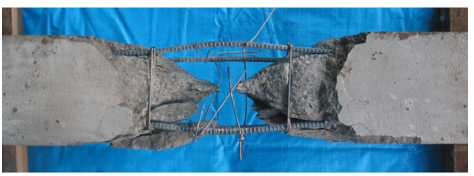

(b) $\mathrm{C} 15-\mathrm{Fc} 50 \mathrm{P} 09 \mathrm{H} 10$

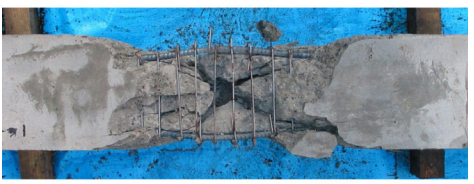

(c) $\mathrm{C} 15-\mathrm{Fc} 50 \mathrm{P} 09 \mathrm{H} 26$

(Fujikake and Aemlaor [6])

Figure 14: Influence of rebar arrangement on damage of RC column specimens with a compressive strength of $51.6 \mathrm{MPa}$ and a longitudinal reinforcement ratio of $0.9 \%$, (modeling of steel bars as solid elements).

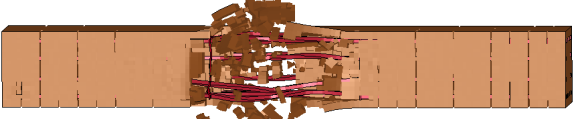

C15 FC50 P25 H0

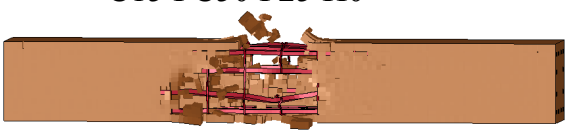

C15 FC50 P25 H10

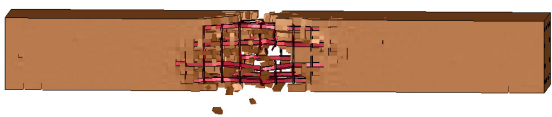

C15 FC50 H25 H26

Present work

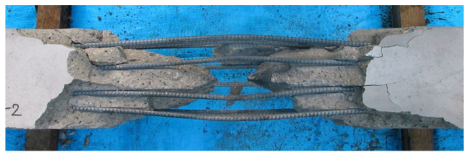

(a) $\mathrm{C} 15-\mathrm{F} 50 \mathrm{P} 25 \mathrm{HO}$

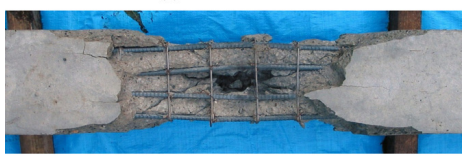

(b) $\mathrm{C} 15-\mathrm{Fc} 50 \mathrm{P} 25 \mathrm{H} 10$

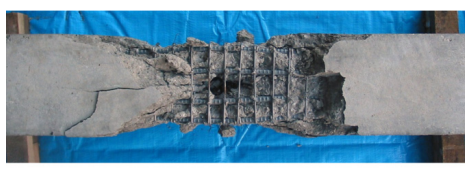

(c) $\mathrm{C} 15-\mathrm{Fc} 50 \mathrm{P} 25 \mathrm{H} 26$

(Fujikake and Aemlaor [6])

Figure 15: Influence of rebar arrangement on damage of RC column specimens with a compressive strength of $51.6 \mathrm{MPa}$ and a longitudinal reinforcement ratio of $2.5 \%$ (modelling of steel bars as solid elements). 


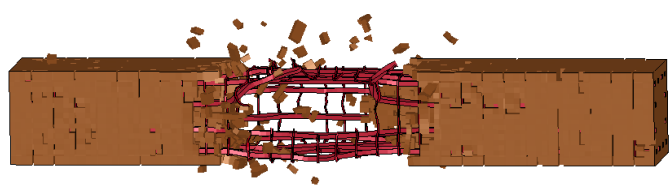

(a) C60 FC50 P25 H26

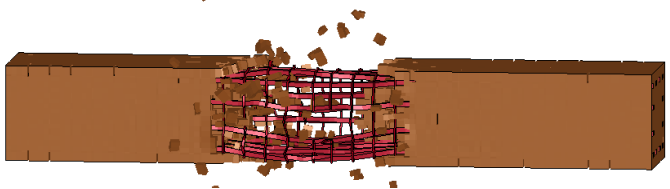

(b) C40 FC50 P25 H26

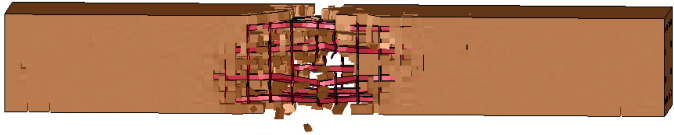

(c) $\mathrm{C} 15 \mathrm{FC} 50 \mathrm{H} 25 \mathrm{H} 26$

Figure 16: Influence of explosive factor on the damage of $\mathrm{RC}$ column specimens with a compressive strength of $51.6 \mathrm{MPa}$ and a longitudinal reinforcement ratio of $2.5 \%$ (numerical studies).

\section{(IV) Influence of concrete strength on the damage of $\mathrm{RC}$ columns, without} shear reinforcement, by explosion

Numerical studies for concrete grade strengths 50 and $90 \mathrm{MPa}$ and longitudinal reinforcement ratios $0.9 \%$ with shear reinforcement ratio $0 \%$ and explosive factor of $0.15 \mathrm{~kg} / \mathrm{m} 2$ have been carried out. Figures 17(a) and 18(a) show the damaged RC column specimens obtained by blasting cases of C15-Fc50P09H0 and $\mathrm{C} 15-\mathrm{Fc} 90 \mathrm{P} 09 \mathrm{H} 0$ respectively using LS-DYNA program.

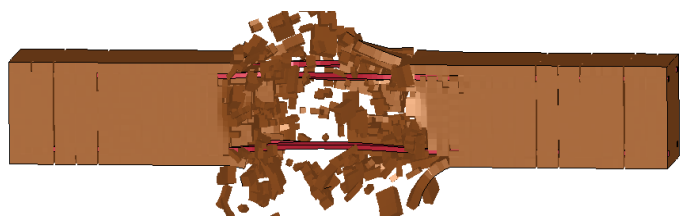

(a) Present study

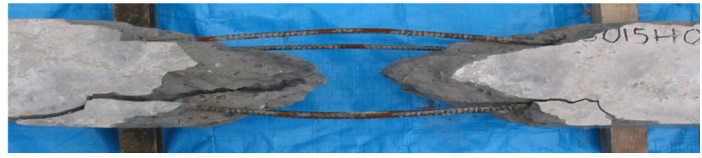

(b) (Fujikake and Aemlaor [6])

Figure 17: Effect of concrete grading FC90 on the damage of RC column specimens with a longitudinal reinforcement ratio of $0.9 \%$, C15 FC90 P09 H0. 
The results obtained by LS-DYNA program for the damage of RC column specimens are in good agreement with the experimental test results carried out by Fujikake and Aemlaor [6] (17(b) and 18(b)). These results indicate that there is no significant effect for the concrete grade on the damaged shape of the RC column.

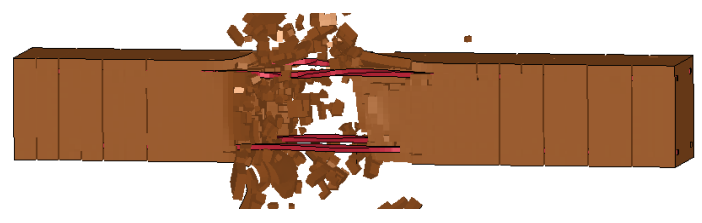

(a) Present study

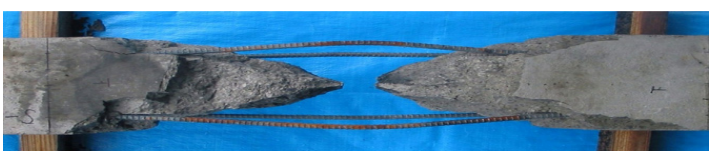

(b) (Fujikake and Aemlaor [6]

Figure 18: Effect of concrete grading FC50 on the damage of RC column specimens with a longitudinal reinforcement ratio of $0.9 \%, \mathrm{C} 15 \mathrm{FC} 50$ P09 H0.

\section{Conclusion}

Based on the extensive research study carried out through this paper, the following conclusions can be stated:

1. A fully three-dimensional numerical model to idealize RC columns with different geometrical and loading conditions subject to demolition by blasting is proposed through LS-DYNA program. Arbitrary Lagrangian/Eulerian (ALE) finite element solution methodology and special aspects for modelling i.e. erosion, hourglass and contact modelling have been included through this model.

2. The numerical applications show that the proposed model is capable to reproduce the physical processes in a realistic manner. The computed damage patterns of $\mathrm{RC}$ columns under demolition blasting assigned by the model are in excellent agreement with available experiment work performed in the field.

3. Simulating concrete volume and steel reinforcement bars as solid elements in the finite element modeling of damaged RC columns represents a reliable solution for obtaining behavior of these columns conforming with their real behavior when tested for demolition by blasting. 
4. To shatter and clear the core concrete of RC columns by blast, the explosive factors should be set at $0.4-0.6 \mathrm{~kg} / \mathrm{m}^{2}$. It should be noted that it is impossible to cut the longitudinal rebar by the explosion in a blasting hole, while it may be possible to blow the shear rebar off.

5. The present numerical study and available experimental test results for RC columns with variable concrete grade strength and longitudinal reinforcement ratio indicate that there is no significant difference in the damage patterns of RC column having no shear reinforcement. On the other hand, the amount of shear reinforcement significantly affects the damage patterns of the RC column after blasting.

\section{References}

[1] Loizeaux, M., and Osborn, A.E. (2006) "Progressive Collapse - An Implosion Contractor's Stock in Trade" Journal of Performance of Constructed Facilities, vol. 20, No 4, pp. 391-402.

[2] Mattern S, Blankenhorn G, Schweizerhof K. (2006) "Computer-aided destruction of complex structures by blasting." In: High performance computing in science and engineering, Springer; 449-57.

[3] Mattern S, Blankenhorn G, Schweizerhof K. (2006) "Numerical analysis of building collapse - Case scenarios and validation". Proceedings of the NATO Advanced Research Workshop, PST.ARW981641, ed.: A. Ibrahimbegovic and I. Kozar.

[4] Isobe D, Eguchi M, Imanishi K, Sasaki Z. (2007) Development of analytical and experimental systems for blast demolition of framed structures. J Struct Construct Eng; 612:73-8.

[5] Riisgaard A., Mendis P., and Gupta A., Ngo T. (2006) "Enhancing the performance under close-in detonations with polymer reinforced CRC", Electronic Journal of Structural Engineering, no 6.

[6] Fujikake K, and Aemlaor P., (2011), "Damage of reinforced concrete columns under demolition blasting" Journal Engineering Structures.

[7] Lupoae M., Baciu C., Constantin D., and Bucur C. (2012) “ The Influence of the Reinforcement on RC Elements Demolition using Explosives" Proceedings of the World Congress on Engineering, WCE 2012, London, U.K.

[8] Agardh, L., (1999) "Validation of numerical simulations of structural response via material sample testing and Field Trials", 3rd Asia-Pacific Conference on Shock \& Impact Loads on Structures, pp.1-14, Singapore.

[9] Lippanen J., (2002) "Dynamic Behaviour of Concrete Structures Subjected to Blast and Fragment Impact", Ph. D Thesis, Chalmers University, Sweden.

[10] Neilsen, M.K., Morgan, H.S., and Krieg, R.D., (1987) “A Phenomenological Constitutive Model for Low Density Polyurethane Foams, "Rept. Sandia National Laboratories, Albuquerque, N.M. 
[11] Broadhouse B.J., (1995), "The Winfrith Concrete Model in LSDYNA3D," Report: SPD/D (95)363, Structural Performance Department, AEA Technology, Winfrith Technology Centre, U.K.

[12] Krieg, R.D. and Key, S.W., (1976), Implementation of a Time Dependent Plasticity Theory into Structural Computer Programs, Vol. 20 of Constitutive Equations in Viscoplasticity; Computational and Engineering Aspects (American Society of Mechanical Engineers, New York, N.Y., pp. 125-137.

[13] LS-DYNA Keyword Users Manual (2010) - Nonlinear Dynamic Structural Analysis of Structures - Version 971 r5", Livermore Software Technology Corporation (LSTC).

[14] LS-DYNA Theoretical Manual, (2006), Livermore Software Technology Corporation (LSTC).

[15] Malvar, L. and Ross, C. (1998). "Review of strain rate effects for concrete in tension". ACI Material Journal. 95:6, 735-739.

[16] Zeng X., Xu B. and Zhang X.Z. (2012) "Experimental Study on Axial Compression Behaviour of RC Columns under Rapid Loadings" 15 WCEE, Lisbona.

[17] Mader, C. L. (2007). "Numerical Modelling of Explosives and Propellants", 3rd edition, CRC Press.

[18] Alia, A. and Souli, M. (2006). "High explosive simulation using multimaterial formulations". Applied Thermal Engineering, 26(10), 1032-1042.

[19] Luccioni, B. and Aráoz, G. (2011). "Erosion Criteria for Frictional Materials under Blast Load", Mechanic Computational Vol. XXX, Rosario, Argentina, pp. 1809-1831. 